\title{
Transcatheter valve-in-valve implantation for the treatment of stentless aortic valve dysfunction
}

\author{
Josep Rodés-Cabau, MD, FESC, Eric Dumont, MD, Daniel Doyle, MD, and Jerôme Lemieux, MD, \\ Quebec City, Quebec, Canada
}

Video clip is available online.

Reoperation for the treatment of stentless aortic valve dysfunction has been shown to be technically challenging and associated with a high operative mortality. ${ }^{1}$ Transcatheter aortic valve implantation (TAVI) is emerging as an alternative to surgical aortic valve replacement for the treatment of patients with severe aortic stenosis who are considered to be at very high or prohibitive surgical risk. However, very few data exist on the use of TAVI for the treatment of bioprosthesis dysfunction. In this report we describe the use of TAVI for the treatment of stentless aortic bioprosthesis dysfunction.

\section{CLINICAL SUMMARY}

An 84-year-old woman was admitted to our hospital because of pulmonary edema. She had a history of hypertension, diabetes, prior stroke, chronic renal failure, coronary artery disease, peripheral vascular disease, and aortic valve replacement with a 23-mm Freestyle valve (Medtronic, Irvine, Calif) placed by using the subcoronary technique 13 years ago. Coronary angiographic analysis showed occlusion of the right coronary artery, and aortographic analysis demonstrated severe aortic regurgitation (Figure 1,A). Doppler echocardiographic analysis showed the presence of severe transvalvular aortic regurgitation (Figure $1, B$ and $C$, and Video 1), a mean aortic gradient of $8 \mathrm{~mm} \mathrm{Hg}$, and normal left ventricular ejection fraction. The patient was declined for conventional surgical aortic valve replacement (Society of Thoracic Surgeons score, $47.9 \%$ ), and she was then evaluated for TAVI. The presence of peripheral vascular disease precluded a retrograde approach through the femoral artery, and transapical TAVI was then proposed.

From the Quebec Heart Institute and Lung Institute, Laval University, Quebec City, Quebec, Canada.

Disclosures: Drs Eric Dumont and Josep Rodés-Cabau are consultants for Edwards Lifesciences, Inc.

Received for publication July 5, 2009; revisions received July 17, 2009; accepted for publication July 31, 2009; available ahead of print Sept 27, 2009.

Address for reprints: Josep Rodés-Cabau, MD, FESC, Quebec Heart and Lung Institute, 2725 chemin Ste-Foy, G1V 4G5 Quebec City, Quebec, Canada (E-mail: josep. rodes@crhl.ulaval.ca).

J Thorac Cardiovasc Surg 2010;140:246-8

$0022-5223 / \$ 36.00$

Copyright (c) 2010 by The American Association for Thoracic Surgery

doi:10.1016/j.jtcvs.2009.07.073

The procedure was authorized by Health Canada under compassionate special access.

The procedure was performed in the operating room by a team of cardiac surgeons and interventional cardiologists using techniques extensively detailed in previous reports (Video 2). ${ }^{2}$ On the basis of an aortic annulus measurement of $20 \mathrm{~mm}$ made by means of transesophageal echocardiographic (TEE) analysis, a 23-mm Edwards SAPIEN valve (Edwards Lifesciences, Inc, Irvine, Calif) was selected for implantation. Because of the lack of appropriate angiographic markers (no valve calcification and no radiopaque markers in the Freestyle valve), the procedure was mainly guided by TEE. After identifying the aortic bioprosthesis by means of TEE (Figure 1,D), the Edwards SAPIEN valve was positioned at the level of the bioprosthetic valve. The hinge point of the anterior mitral leaflet was also used as an anatomic marker for positioning the ventricular end of the valve. Valve deployment was performed under rapid pacing (Figure 2, $A$ and $B$, and Video 3). Doppler echocardiographic analysis showed a mean residual aortic gradient and aortic valve area of $17 \mathrm{~mm} \mathrm{Hg}$ and $1.10 \mathrm{~cm}^{2}$, respectively, and trivial central aortic regurgitation (Figure 2, C and $D$, and Videos 4 and 5). The postoperative period was uneventful, and the patient was discharged 7 days after the procedure. At 1 month's follow-up, the patient was in New York Heart Association functional class II, and there were no changes in the echocardiographic parameters.

\section{DISCUSSION}

$\mathrm{Ng}$ and colleagues ${ }^{3}$ reported the use of TAVI for the treatment of a significant paravalvular leak in a patient with a Freestyle aortic bioprosthesis. The present case shows the feasibility of treating a severe aortic regurgitation caused by structural deterioration of a Freestyle aortic bioprosthesis by using the transapical TAVI approach with the Edwards SAPIEN valve and represents 1 step further in the use of TAVI for the treatment of stentless aortic valve dysfunction. To date, TAVI has been limited to the treatment of severe calcific aortic stenosis, and the presence of calcium has been considered a key factor in facilitating valve anchoring and avoiding embolization. Wenaweser and associates ${ }^{4}$ reported the first case of TAVI for the treatment of a dysfunctional stented aortic bioprosthesis. However, TAVI for the treatment of stentless bioprosthesis dysfunction is a more challenging procedure because of the lack of landing support (stent) for the anchoring of the transcatheter valve. Also, the absence of radiopaque markers makes the positioning of the transcatheter valve 

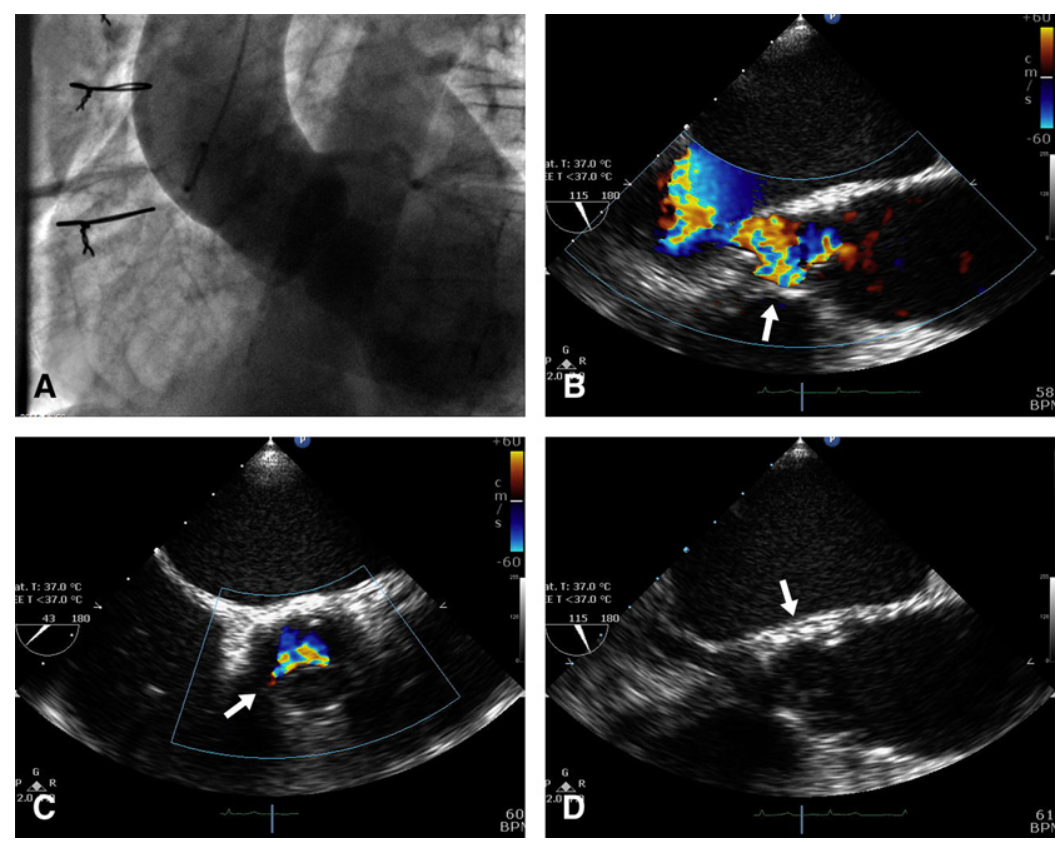

FIGURE 1. Aortographic and transesophageal echocardiographic images before transcatheter aortic valve implantation. A, Aortographic image showing severe aortic regurgitation. B, Transesophageal echocardiographic image (long-axis view) showing the severity of aortic regurgitation (white arrow). C, Transesophageal echocardiographic image (short-axis view) showing the transvalvular origin of aortic regurgitation. D, Transesophageal echocardiographic image (long-axis view) depicting the Freestyle aortic valve as an echodense linear structure parallel to the aortic wall (white arrow).

much more difficult. We have previously showed the role of TEE in guiding TAVI procedures, ${ }^{5}$ and the present report provides further insight into the importance of such an imaging technique for guiding TAVI procedures. In our experience the use of echocardiographic landmarks, such as the hinge point of the mitral valve, and the possibility of visualizing the stentless aortic valve with TEE played a major role in the correct positioning of the transcatheter valve.
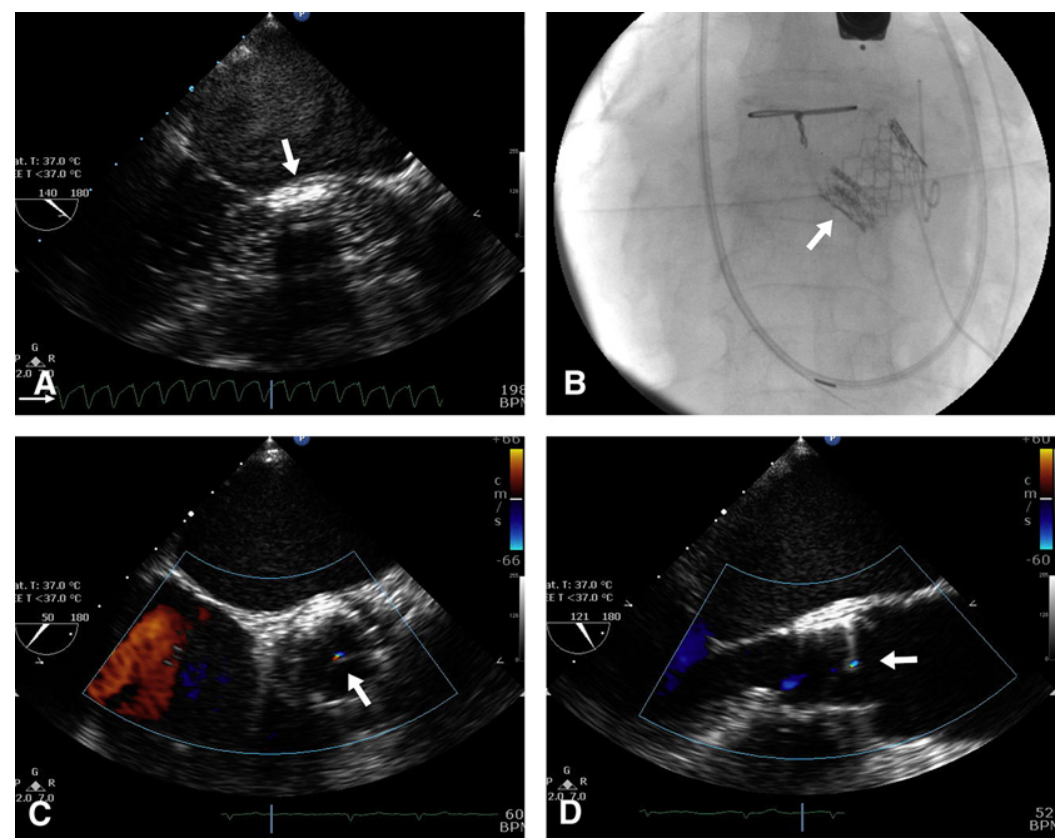

FIGURE 2. Procedural and postprocedural transesophageal echocardiographic and fluoroscopic images. A, Echocardiographic image showing the transcatheter aortic valve implantation by balloon inflation (thick white arrow) under rapid pacing (thin white arrow). B, Fluoroscopic image (posteroanterior view) of the transcatheter valve (white arrow) after valve implantation. C and D, Transesophageal echocardiographic images (C, long-axis view; D, short-axis view) showing trivial aortic regurgitation (white arrows) after valve implantation. 
In conclusion, this report shows the feasibility of TAVI for the treatment of structural deterioration of a stentless aortic bioprosthesis, suggesting that TAVI might be further considered for the treatment of this highly challenging subset of patients. However, the efficacy and safety of this strategy should be determined in prospective studies with a large number of patients and long-term follow-up.

We thank Drs Sebastien Bergeron, Jacques Villeneuve, Robert DeLarochellière, and Rodrigo Bagur from the Laval Hospital and Mark Dedahstian, MS, from Edwards Lifesciences, Inc, for their help during the procedure and the careful review of the manuscript. We also thank Marie-Annick Clavel, MSc, for technical assistance.

\section{References}

1. Borger MA, Prasongsukarn K, Armstrong S, Feindel CM, David TE. Stentless aortic valve reoperations: a surgical challenge. Ann Thorac Surg. 2007;84:737-43.

2. Rodés-Cabau J, Dumont E, DelaRochellière R, Doyle D, Lemieux J, Bergeron S, et al. Feasibility and initial results of percutaneous aortic valve implantation including selection of the transfemoral or transapical approach in patients with severe aortic stenosis. Am J Cardiol. 2008;102:1240-6.

3. Ng ACT, van der Kley F, Delgado V, Shanks M, van Bommel RJ, de Wegger A, et al. Percutaneous valve-in-valve procedure for severe paravalvular regurgitation in aortic bioprosthesis. JACC Cardiovasc Imaging. 2009;2:522-3.

4. Wenaweser P, Buellesfeld L, Gerckens U, Grube E. Percutaneous aortic valve replacement for severe aortic regurgitation in degenerated bioprosthesis: the first valve in valve procedure using the Corevalve Revalving system. Catheter Cardiovasc Interv. 2007;70:760-4.

5. Dumont E, Lemieux J, Doyle D, Rodés-Cabau J. Feasibility of transapical aortic valve implantation fully guided by transesophageal echocardiography. $J$ Thorac Cardiovasc Surg. 2009 [Epub ahead of print].

\title{
Balloon-guided, tapered, Polyflex stent guidance: An atraumatic technique for successful stent placement through tight, rigid airway stenoses
}

\author{
Moishe Liberman, MD, ${ }^{\mathrm{a}}$ and John C. Wain, MD, ${ }^{\mathrm{b}}$ Montreal, Quebec, Canada, and Boston, Mass
}

Supplemental material is available online.

Benign airway strictures are often effectively treated with sequential dilation. However, when this is not successful, or in cases of frequent stricture recurrence, retrievable stenting can relieve symptoms as well as allow for airway remodeling, resulting in a less stenotic lumen. Anastomotic strictures are often difficult to dilate owing to fibrosis and suture reaction. Reoperation in these cases is often extremely challenging owing to the limited length of airway remaining after the first operation. In these cases, we prefer to use silicone stents after dilation to allow stricture remodeling. The Polyflex

From the Division of Thoracic Surgery, ${ }^{\text {a }}$ Centre Hospitalier de l'Université de Montréal, University of Montreal, Montreal, Quebec, Canada; and the Division of Thoracic Surgery, ${ }^{\mathrm{b}}$ Massachusetts General Hospital, Harvard University, Boston, Mass.

Disclosures: None.

Received for publication May 20, 2009; revisions received Sept 14, 2009; accepted for publication Sept 17, 2009; available ahead of print Jan 18, 2010.

Address for reprints: Moishe Liberman, MD, Department of Thoracic Surgery, The Centre Hospitalier de l'Université de Montréal, 1560 rue Sherbrooke Est 8e CD, Room D-8051, Montreal, Quebec, Canada H2L 4M1 (E-mail: moishe.liberman@ umontreal.ca).

J Thorac Cardiovasc Surg 2010;140:248-9

$0022-5223 / \$ 36.00$

Copyright (c) 2010 by The American Association for Thoracic Surgery

doi:10.1016/j.jtcvs.2009.09.061 self-expanding polyester/silicone airway stent (Boston Scientific, Boston, Mass) works well for these challenging cases because it is completely covered, thin-walled, and does not contain any metallic elements.

The main challenge with the Polyflex stent delivery system is that it must be positioned through the area of stenosis. This proves to be extremely difficult in some strictures owing to the inflexibility of the stenosis and the blunt, rigid, stent insertion system (Figure 1). The stent delivery device is nondeformable in its undeployed state and requires internal stenting to permit atraumatic passage through some strictures. To circumvent this, we insert a pulmonary balloon dilator (CRE pulmonary balloon dilator; Boston Scientific) through the delivery system and then through the stent. The balloon is inflated with the tip protruding from the delivery system by approximately $10 \mathrm{~mm}$ (Figure $2, A$ ). The balloon acts as a tapered tip for the stent delivery system and allows the delivery system to easily traverse the stenosis without traumatizing it. The balloon is guided down to and

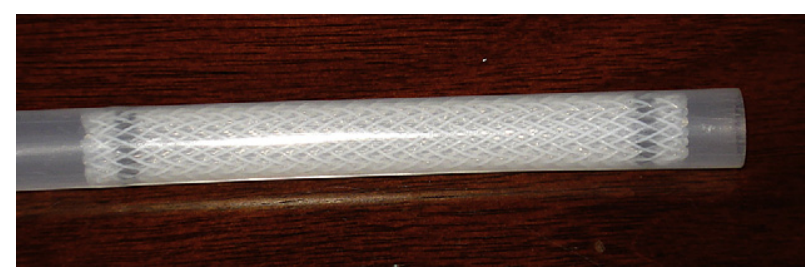

FIGURE 1. The Polyflex stent delivery system. 